\title{
Synthesis, structure and electroluminescent properties of cyclometalated iridium complexes possessing sterically hindered ligands
}

\author{
Marappan Velusamy, ${ }^{a}$ K. R. Justin Thomas, ${ }^{a}$ Chih-Hsin Chen, ${ }^{a}$ Jiann T. Lin, ${ }^{* a}$ Yuh S. Wen, ${ }^{a}$ Wan-Ting Hsieh, ${ }^{b}$ \\ Chin-Hung Lai ${ }^{b}$ and Pi-Tai Chou ${ }^{* b}$
}

\author{
Received 15th December 2006, Accepted 13th March 2007 \\ First published as an Advance Article on the web 30th March 2007 \\ DOI: 10.1039/b618311e
}

New CN donor ligands incorporating pyridine or benzoimidazole $\mathrm{N}$ donors and a sterically hindered cyclometalating aromatic core featuring a polyphenylenephenyl, fluoranthene, or triphenylene segment are prepared and successfully converted into heteroleptic iridium(III) cyclometalated complexes with acetylacetone auxiliary ligands. The X-ray structure of the complex, derived from a ligand containing a fluoranthene fragment, has been solved to unveil the corresponding structure. The results clearly demonstrate that the nature of the $\sigma$-coordinating ligand segment plays a key role in dictating the emission profile and peak position, such that the emission hue has been successfully tuned ranging from green to red. Supplementary support of this viewpoint is also rendered by computational (DFT) approaches. Electroluminescent devices fabricated using a complex as dopant in the PVK matrix were found to exhibit bright greenish yellow emission with promising device characteristics (maximum brightness $26450 \mathrm{~cd} \mathrm{~m}^{-2}$ at $30 \mathrm{~V}$ and a maximum current efficiency of $40 \mathrm{~cd} \mathrm{~A}^{-1}$ ).

\section{Introduction}

There is considerable interest in the synthesis and characterization of cyclometalated iridium(III) complexes due to their use in lightemitting diodes (LED) ${ }^{1}$ and as biological labelling agents. ${ }^{2}$ Lightemitting organometallic complexes such as $\mathrm{Ru}(\mathrm{II})$ polypyridine complexes $^{3}$ and Ir(III) complexes ${ }^{1,4}$ are explored for LED applications because they offer the possibility of reaping both singlets and triplets formed during the LED operation. ${ }^{5}$ In contrast, while some polymers have been reported to facilitate triplet harvesting, ${ }^{6}$ small organic molecules usually lack this feature.

In view of iridium(III) complexes, iridium(III) cyclometalated complexes containing $\mathrm{N}$-donor motifs such as pyridine, ${ }^{7}$ benzothiazole, ${ }^{8}$ benzoimidazole, ${ }^{9}$ quinoline,${ }^{10}$ and pyrazole ${ }^{11}$ were prepared. Additional anionic auxiliary ligands such as acetylacetone, pyridine-2-carboxalic acid, ${ }^{12}$ triazoles $^{13}$ and pyrazoles ${ }^{14}$ were also used in the synthesis of heteroleptic complexes. Recently, dendritic $^{15}$ and polymer ${ }^{16}$ based ligands have also been developed and used for the construction of Ir(III) complexes. These macromolecules inherit additional benefits such as chromophore isolation (preventing unwanted interchromophoric interactions that often lead to emission quenching and emission profile alteration), energy harvesting emission enhancement, and simple device fabrication procedures.

Polyphenylenephenyl dendrons, often termed as Müllen-type dendrons, have been widely used in recent designs to probe inter-chromophoric interactions such as energy and electron transfer. ${ }^{17}$ Organic molecules incorporating these dendrons were found to emit intense blue ${ }^{18}$ or red $^{19}$ colors in electroluminescent

anstitute of Chemistry, Academia Sinica, 115 Nankang, Taipei, Taiwan. E-mail: jtlin@chem.sinica.edu.tw; Fax: +8862 278313771; Tel: +886-227898522

${ }^{b}$ Department of Chemistry, National Taiwan University, Taipei, Taiwan. E-mail: chop@ntu.edu.tw; Fax: +886-2-23695208; Tel: +886-2-33663894 devices. Müllen-type dendrons are rigid and voluminous, thus raising the $T_{\mathrm{g}}$ and thermal stability in addition to minimising the non-radiative pathways. Attempts have also been made to replace the central phenyl core in the polyphenylenephenyl dendrons with other extended conjugated aromatic segments. Accordingly, fluoranthene cored bright blue emitters have been reported recently. ${ }^{20}$ Herein, we report a series of new $\mathrm{CN}$ donor ligands and their Ir(III) cyclometalated complexes (Charts 1 and 2).
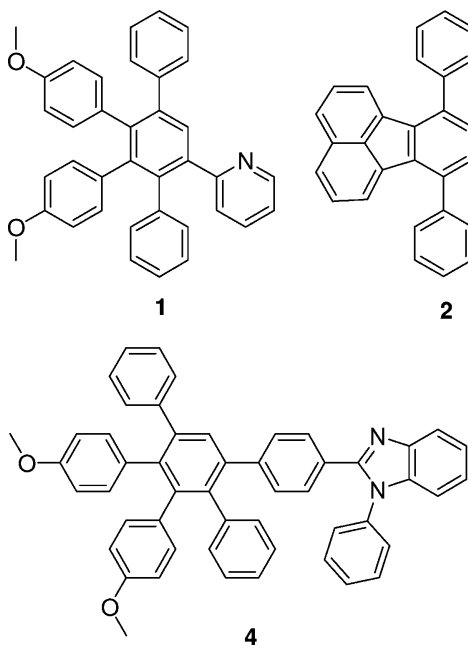

4

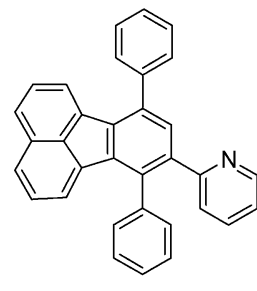

2
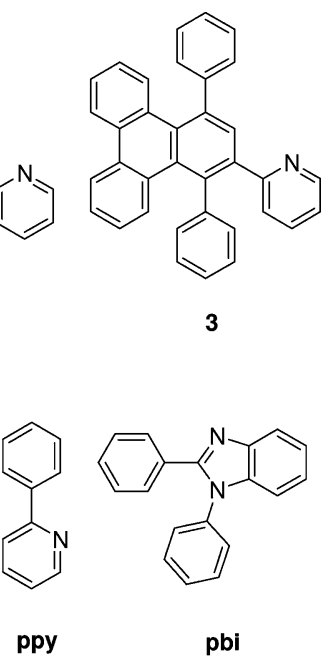

Chart 1

In view of the structure, these ligands can be classified into two categories: in the first, the central phenyl/aryl of the segment participates in cyclometalation (A in Scheme 1), and in the second, a peripheral phenyl farthest from the centroid is involved in coordination (B in Scheme 1). As for the case of $\mathbf{B}$ type ligands, Burn et $a{ }^{15}$ have initiated elegant work regarding the effect of steric crowding in phosphorescent dendrimers. In this study, we 


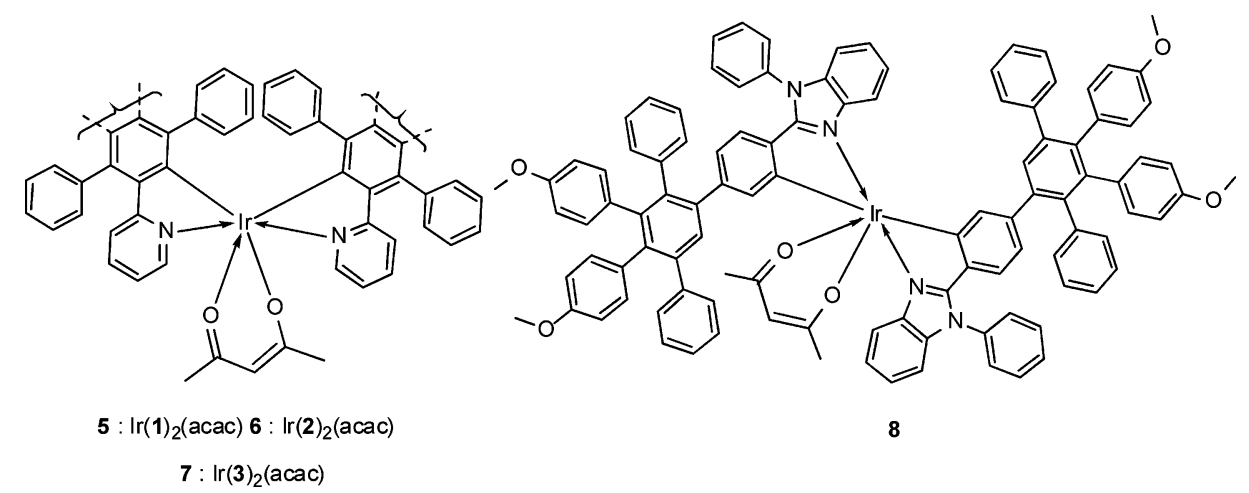

Chart 2

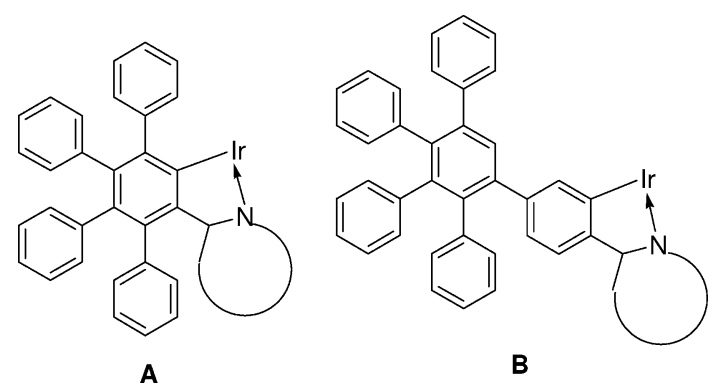

Scheme 1

made further investigations to probe both $\mathbf{A}$ and $\mathbf{B}$ type ligands, and found that, depending on the cyclometalating segment, the emission properties can be fine-tuned ranging from green to red. Consequently, the nature of the $\sigma$-coordinating ligand segment plays a key role in dictating the emission properties.

\section{Experimental}

\section{Methods and materials}

All reactions and manipulations were carried out under $\mathrm{N}_{2}$ with the use of standard inert atmosphere and Schlenk techniques. Solvents were dried by standard procedures. The entire column chromatographic studies were performed under $\mathrm{N}_{2}$ with the use of silica gel (230-400 mesh, Macherey-Nagel GmbH \& Co.) as the stationary phase. The ${ }^{1} \mathrm{H}$ NMR spectra were obtained by using Bruker AC300 or AMX400 spectrometers. Mass spectra were recorded on a JMS-700 double focusing mass spectrometer (JEOL, Tokyo, Japan). Elemental analyses were performed on a PerkinElmer $2400 \mathrm{CHN}$ analyzer. Cyclic voltammetry experiments were performed with a BAS-100 electrochemical analyzer at room temperature with a conventional three-electrode configuration consisting of a glassy carbon working electrode, a platinum wire auxiliary electrode, and a non-aqueous $\mathrm{Ag} / \mathrm{AgNO}_{3}$ reference electrode. The solvent in all experiments was dichloromethane, and the supporting electrolyte was $0.1 \mathrm{M}$ tetrabutylammonium hexafluorophosphate. The $E_{1 / 2}$ values were determined as $1 / 2\left(E_{\mathrm{p}}{ }^{\mathrm{a}}+\right.$ $\left.E_{\mathrm{p}}{ }^{\mathrm{c}}\right)$, where $E_{\mathrm{p}}{ }^{\mathrm{a}}$ and $E_{\mathrm{p}}{ }^{\mathrm{c}}$ are the anodic and cathodic peak potentials, respectively. The potentials are quoted against the ferrocene internal standard. Electronic absorption spectra were obtained on a Perkin Elmer Lambda 900 UV-Vis-NIR spectrophotometer for dichloromethane solutions. Emission spectra were recorded in deoxygenated toluene solution at $298 \mathrm{~K}$ with a Jobin Yvon SPEX Fluorolog-3 spectrofluorimeter. The emission spectra were collected on samples with O.D. (optical density) $<0.1$ at the excitation wavelength. The spectra were corrected for instrumental response. UV-Visible spectra were checked before and after irradiation to monitor possible sample degradation. Emission maxima were reproducible to within $2 \mathrm{~nm}$. Luminescence quantum yields $\left(\Phi_{\text {em }}\right)$ were calculated using quinine sulfate as the primary standard $\left(\Phi_{\mathrm{em}}=0.577\right.$ in $0.1 \mathrm{M}$ sulfuric acid $)$ and $\operatorname{Ir}(\mathrm{ppy})_{3}\left(\Phi_{\mathrm{em}}=0.40 \mathrm{in}\right.$ toluene) as the secondary reference. ${ }^{21}$ The lifetime was measured with the laser photolysis technique, in which the third harmonic of an Nd:YAG laser ( $8 \mathrm{~ns}$, Continuum Surlite II) was used as the excitation source, coupled with a fast response photomultiplier (Hamamatsu model R5509-72) operated at $-80{ }^{\circ} \mathrm{C}$. Typically, an average of 512 shots was acquired for each measurement.

The starting materials, 3,4-bis(4-methoxy-phenyl)-2,5-diphenylcyclopenta-2,4-dienone, ${ }^{19}$ 7,9-diphenyl-cyclopenta[ $\left.a\right]$ acenaphthylen-8-one, ${ }^{22}$ 1,3-diphenyl-cyclopenta[l]-phenanthren-2-one, ${ }^{23}$ and 2-ethynyl-pyridine, ${ }^{24}$ were prepared by adopting the literature procedures.

\section{Synthesis of the ligands 1-4}

Ligands $2\left[\left\{3^{\prime}, 4^{\prime}-\left(4^{\prime \prime}\right.\right.\right.$-methoxyphenyl)-2',5'-diphenyl $\}$ phenyl $]$ pyridine (1), 2-(7,10-diphenyl-fluoranthen-8-yl)-pyridine (2), and 2-(1,4-diphenyl-triphenylen-2-yl)-pyridine (3) were synthesized from 2-ethynylpyridine on reaction with 3,4-bis-(4-methoxyphenyl)-2,5-diphenyl-cyclopenta-2,4-dienone, 7,9-diphenyl-cyclopenta[a]acenaphthylen-8-one, and 1,3-diphenyl-cyclopenta[1]phenanthren-2-one, respectively. Ligand 2-[(3',4'-bis(4"'-methoyphenyl)-2',5'-diphenyl)-biphenyl-4-yl]-1-phenyl-1H-benzo( $d$ )imidazole 4 was synthesized from 3,4-bis-(4-methoxy-phenyl)-2,5diphenyl-cyclopenta-2,4-dienone in reaction with 2-ethynyl1-phenyl-1 $H$-benzoimidazole. The detailed procedure for the preparation of ligand $\mathbf{1}$ is discussed here and the same procedure is followed for the other ligands.

Synthesis of ligand 1. A stirred mixture of 2-ethynylpyridine (0.61 g, $6 \mathrm{mmol})$ and 3,4-bis-(4-methoxy-phenyl)-2,5-diphenylcyclopenta-2,4-dienone (2.2 g, $5 \mathrm{mmol}$ ) in degassed diphenyl ether $(15 \mathrm{~mL})$ was refluxed for $15 \mathrm{~h}$. At the completion of the reaction water was added to quench the reaction. The product was extracted with diethyl ether. The organic layer was collected, dried over anhydrous $\mathrm{MgSO}_{4}$, and evaporated under vacuum. The solid was 
adsorbed on silica gel and purified by column chromatography, using a $\mathrm{CH}_{2} \mathrm{Cl}_{2}$-hexane mixture as eluent to give $\mathbf{1}$ as a white solid $(2.0 \mathrm{~g}, 80 \%) .{ }^{1} \mathrm{H} \mathrm{NMR}\left(\delta, \mathrm{CDCl}_{3}\right): 3.61\left(\mathrm{~s}, 3 \mathrm{H}, \mathrm{OCH}_{3}\right), 3.63(\mathrm{~s}, 3 \mathrm{H}$, $\left.\mathrm{OCH}_{3}\right), 6.40-6.47$ (m, 4H, OCH$\left.{ }_{3}-\mathrm{Ar}\right), 6.63-6.71$ (m, 4H, $\mathrm{OCH}_{3}$ Ar), 6.85-6.87 (m, 3H, Ar), 6.93-6.94 (m, 3H, Ar), 7.04-7.13 (m, $6 \mathrm{H}, \mathrm{Ar}), 7.33$ (t, $J=7.3 \mathrm{~Hz}, 1 \mathrm{H}$, pyridyl), 7.73 (s, 1H, central Ar), $8.55\left(\mathrm{~d}, J=4.56 \mathrm{~Hz}, 1 \mathrm{H}\right.$, pyridyl). ${ }^{13} \mathrm{C} \mathrm{NMR}\left(\delta, \mathrm{CDCl}_{3}\right): 55.0$, $55.1,112.4,112.6,121.3,125.5,125.9,126.2,127.2,127.6,130.1$, $131.2,131.5,132.5,132.6,132.7,135.3,139.5,140.1,140.6,141.5$, $141.7,142.0,148.9,157.3,157.5,158.5 ; \operatorname{FAB} \mathrm{MS}(\mathrm{m} / \mathrm{z}): 520.1(\mathrm{M}+$ $\mathrm{H})^{+}$. FAB-HRMS calc. for $\mathrm{C}_{37} \mathrm{H}_{30} \mathrm{NO}_{2}[\mathrm{M}+\mathrm{H}]^{+}: 520.2277$ found: 520.2290 .

Ligand 2. ${ }^{1} \mathrm{H}$ NMR $\left(\delta, \mathrm{CDCl}_{3}\right): 6.71(\mathrm{~d}, 1 \mathrm{H}, J=7.2 \mathrm{~Hz}$, pyridyl), 7.0-7.05 (m, 2H, pyridyl), 7.26-7.30 (m, 2H, Ar), 7.34$7.42(\mathrm{~m}, 7 \mathrm{H}, \mathrm{Ar}), 7.46-7.54(\mathrm{~m}, 3 \mathrm{H}$, fluoranthene and Ar), 7.59 (s,1H, central Ar), 7.68-7.74 (m, 4H, fluoranthene), $8.56(\mathrm{~d} 1 \mathrm{H}$, $J=4.5 \mathrm{~Hz}$, pyridyl). ${ }^{13} \mathrm{C} \mathrm{NMR}\left(\delta, \mathrm{CDCl}_{3}\right): 121.4,123.4,123.5$, $125.5,126.8,127.0,127.6,127.7,127.8,127.9,128.7,128.8,129.3$, 129.4, 129.8, 130.4 131.3, 133.3, 135.5, 135.9, 136.1, 136.6, 137.0, 138.2, 138.3, 139.2, 140.8, 148.9, 158.6. $\operatorname{FAB} \operatorname{MS}(m / z): 431\left(\mathrm{M}^{+}\right)$. FAB-HRMS calc. for $\mathrm{C}_{33} \mathrm{H}_{22} \mathrm{~N}[\mathrm{M}+\mathrm{H}]^{+}$: 432.1752 found: 432.1760 .

Ligand 3. ${ }^{1} \mathrm{H}$ NMR $\left(\delta, \mathrm{CDCl}_{3}\right): 6.63(\mathrm{~d}, 1 \mathrm{H}, J=7.2 \mathrm{~Hz}$, pyridyl), 6.98 (m, 1H, pyridyl), 7.08-7.20 (m, 7H, Ar), 7.34-7.51 (m, $9 \mathrm{H}, \mathrm{Ar}), 7.75$ (d, $1 \mathrm{H}, J=8.43 \mathrm{~Hz}$, pyridyl), 7.85 (s, 1H, central Ar), 8.42 (d, $2 \mathrm{H}, J=8.2 \mathrm{~Hz}, \mathrm{Ar}), 8.62(\mathrm{~d}, 1 \mathrm{H}, J=4.9 \mathrm{~Hz}$, pyridyl). ${ }^{13} \mathrm{C}$ NMR $\left(\delta, \mathrm{CDCl}_{3}\right): 121.3,123.3,123.4,125.4,125.7$, 126.6, 126.9, 127.0, 127.3, 128.8, 129.1, 129.8, 130.0, 130.3, 130.8, 131.2, 131.6, 131.7, 131.8, 132.0, 132.1, 135.1, 136.7, 138.7, 142.1, 144.5, 149.2, 159.6. FAB MS $(m / z)$ : $457.1\left(\mathrm{M}^{+}\right)$. FAB-HRMS calc. for $\mathrm{C}_{35} \mathrm{H}_{24} \mathrm{~N}\left[\mathrm{M}+\mathrm{H}^{+}\right.$: 458.1909 found: 458.1909 .

Ligand 4. ${ }^{1} \mathrm{H}$ NMR $\left(\delta, \mathrm{CDCl}_{3}\right): 3.62\left(\mathrm{~s}, 3 \mathrm{H}, \mathrm{OCH}_{3}\right), 3.65$ (s, 3H, $\left.\mathrm{OCH}_{3}\right), 6.44-6.52$ (m, 4H, $\left.\mathrm{OCH}_{3}-\mathrm{Ar}\right), 6.68-6.77$ (m, 4H, $\mathrm{OCH}_{3}$-Ar), 6.81-6.82 (m, 2H, Ar), 6.93-6.94 (m, 3H, Ar), 7.087.18 (m, 7H, Ar), 7.25-7.28 (m, 4H, Ar), 7.31-7.34 (m, 1H, Ar), 7.36-7.39 (m, 2H, Ar), 7.46-7.48 (m, 3H, Ar), 7.53 (s, 1H, centralAr), $7.89\left(\mathrm{~d}, 1 \mathrm{H}, J=8.2 \mathrm{~Hz}\right.$, benzimidazole-Ar). ${ }^{13} \mathrm{C}$ NMR $\left(\delta, \mathrm{CDCl}_{3}\right): 55.1,110.5,112.4,112.7,119.0,119.8,123.2,123.5$, $125.8,126.3,127.2,127.5,127.6,127.8,128.6,128.9,129.9,130.0$, $131.2,131.6,132.4,132.5,132.6,132.8,137.0,137.2,139.7,139.8$, 140.0, 141.2, 141.8, 142.0, 143.0, 143.3, 152.4, 157.3, 157.5. FAB $\mathrm{MS}(\mathrm{m} / \mathrm{z}): 710.1\left(\mathrm{M}^{+}\right)$. FAB-HRMS calculated for $\mathrm{C}_{51} \mathrm{H}_{39} \mathrm{~N}_{2} \mathrm{O}_{2}$ $[\mathrm{M}+\mathrm{H}]^{+}: 711.3012$ found: 711.3019 .

\section{Synthesis of the complexes 5-8}

Complexes 5-8 were synthesized by similar procedures, as followed for complex 5 .

Synthesis of complex 5. A mixture of $\mathbf{1}(0.62 \mathrm{~g}, 1.2 \mathrm{mmol})$, $\mathrm{IrCl}_{3} \cdot x \mathrm{H}_{2} \mathrm{O}(0.15 \mathrm{~g}, 0.5 \mathrm{mmol})$, 2-methoxyethanol $(6 \mathrm{~mL})$, and distilled water $(3 \mathrm{~mL})$ was heated at reflux for $12 \mathrm{~h}$. After cooling, the yellow precipitate which formed was filtered off and washed with methanol $(50 \mathrm{~mL})$, diethyl ether $(50 \mathrm{~mL})$, and hexane (20 $\mathrm{mL})$. The dried chlorobridged dimer was suspended in 2methoxyethanol $(5 \mathrm{~mL})$ and treated with acetylacetone $(0.10 \mathrm{~g}$, $1 \mathrm{mmol})$ and anhydrous $\mathrm{Na}_{2} \mathrm{CO}_{3}(0.16 \mathrm{~g}, 1.5 \mathrm{mmol})$. The reaction mixture was stirred at $80{ }^{\circ} \mathrm{C}$ for $8 \mathrm{~h}$. The insoluble products were filtered off, washed with water $(10 \mathrm{~mL})$, methanol $(10 \mathrm{~mL})$, and diethyl ether $(20 \mathrm{~mL})$, and dried. These insoluble products were dissolved again in dichloromethane $(20 \mathrm{~mL})$, adsorbed on silica gel, and rapidly purified by column chromatography using a hexane-dichloromethane mixture $(3: 2)$. The yellow solid obtained was recrystallized from a dichloromethane-hexane mixture. Yield: $0.10 \mathrm{~g}(80 \%) .{ }^{1} \mathrm{H} \mathrm{NMR}\left(\delta, \mathrm{CDCl}_{3}\right): 1.56$ (s, $6 \mathrm{H}, \mathrm{CH}_{3}$-acac), 3.55 (s, $\left.6 \mathrm{H}, \mathrm{OCH}_{3}\right), 3.59$ (s, 6H, $\left.\mathrm{OCH}_{3}\right), 5.02$ (s, 1H, $\mathrm{CH}$-acac), 5.84 (d, 2H, $J=8.4 \mathrm{~Hz}, \mathrm{Ar}), 6.21-6.22$ (m, 2H, Ar), 6.31-6.39 (m, 16H, Ar), 6.50-6.57 (m, 4H, Ar), 6.62-6.73 (m, 8H, Ar), 7.047.12 (m, 10H, Ar), 7.72-7.74 (m, 2H, Ar). ${ }^{13} \mathrm{C}$ NMR $\left(\delta, \mathrm{CDCl}_{3}\right)$ : 14.2, 28.6, 31.0, 53.5, 54.9, 55.0, 99.5, 111.5, 111.8, 111.9, 119.2, 123.1, 123.9, 125.4, 125.5, 126.0, 128.0, 128.1, 130.1, 130.7, 131.0, $132.1,132.5,132.6,132.7,133.0,134.0,134.3,134.6,135.3,139.8$, 142.5, 143.8, 145.6, 149.1, 156.4, 156.5, 167.7, 184.0, 206.9; FAB $\operatorname{MS}(\mathrm{m} / z)$ : $1328.2\left(\mathrm{M}^{+}\right)$. Anal. Calcd for $\mathrm{C}_{79} \mathrm{H}_{63} \mathrm{IrN}_{2} \mathrm{O}_{6}$ : C, 71.42; H, 4.78; N, 2.11. Found: C, 71.21; H, 4.88; N, 2.05\%.

Complex 6. Yield: $55 \%{ }^{1} \mathrm{H} \mathrm{NMR}\left(\delta, \mathrm{CDCl}_{3}\right): 1.59\left(\mathrm{~s}, 6 \mathrm{H}, \mathrm{CH}_{3}\right.$ acac), 4.87 (s, 1H, CH-acac), 5.53 (d, 2H, $J=7.2 \mathrm{~Hz}, \mathrm{Ar}), 6.08$ (d, $2 \mathrm{H}, J=7.2 \mathrm{~Hz}, \mathrm{Ar}), 6.27$ (d, 2H, $J=8.5 \mathrm{~Hz}, \mathrm{Ar}), 6.59-6.63$ (m, 4H, Ar), 6.76-6.89 (m, 2H, Ar), 6.9-7.02 (m, 10H, Ar), 7.14-7.16 (m, 2H, Ar), 7.47-7.55 (m, 6H, Ar), 7.61-7.62 (m, 4H, Ar), 7.72$7.74(\mathrm{~m}, 4 \mathrm{H}, \mathrm{Ar}), 8.13-8.15(\mathrm{~m}, 2 \mathrm{H}, \mathrm{Ar}) .{ }^{13} \mathrm{C} \mathrm{NMR}\left(\delta, \mathrm{CDCl}_{3}\right)$ : 14.2, 22.7, 28.5, 31.7, 99.6, 118.9, 121.5, 122.6, 123.4, 124.9, 125.5, $125.9,126.9,127.2,127.4,127.5,129.0,129.2$, 129.5, 129.6, 129.7, $130.2,130.6,133.5,134.9,136.0,137.2,137.4,138.0,142.1,143.0$, $144.5,146.5,149.0,149.5,167.3,184.5 . \operatorname{FAB} \operatorname{MS}(m / z): 1152.3$ $\left(\mathrm{M}^{+}\right)$. Anal. Calcd for $\mathrm{C}_{71} \mathrm{H}_{47} \mathrm{IrN}_{2} \mathrm{O}_{2}$ : C, 74.00; H, 4.11; N, 2.43 . Found: C, 73.72; H, 4.24; N, 2.36\%.

Complex 7. Yield: $70 \% .{ }^{1} \mathrm{H}$ NMR $\left(\delta, \mathrm{CDCl}_{3}\right): 1.54(\mathrm{~s}, 6 \mathrm{H}$, $\mathrm{CH}_{3}$-acac), 4.98 (s, 1H, CH-acac), 5.75-5.81 (m, 2H, Ar), 6.156.28 (m, 2H, Ar), 6.40-6.41 (m, 1H, Ar), 6.43-6.49 (m, 3H, Ar), 6.50-6.83 (m, 10H, Ar), 6.98-7.01 (m, 5H, Ar), 7.22-7.41 (m, 12H, Ar), 7.53-7.54 (m, 2H, Ar), 7.71-7.73 (m, 1H, Ar), 8.05-8.07 (m, $1 \mathrm{H}, \mathrm{Ar}), 8.28-8.34$ (m, 4H, Ar), 8.54-8.56 (m, 1H, Ar). ${ }^{13} \mathrm{C} \mathrm{NMR}$ $\left(\delta, \mathrm{CDCl}_{3}\right): 28.6,28.8,99.1,99.6,119.3,120.8,122.9,123.4,124.7$, 125.0, 125.1, 125.5, 127.3, 127.6, 128.8, 129.2, 129.7, 130.3, 130.4, $130.5,131.1,131.2,131.9,132.2,132.6,134.3,141.7,143.5,144.2$, 145.0, 146.5, 147.8, 148.8, 150.1, 151.4, 167.2, 167.4, 183.8, 184.5. FAB $\mathrm{MS}(\mathrm{m} / \mathrm{z}): 1204.3\left(\mathrm{M}^{+}\right)$. Anal. Calcd for $\mathrm{C}_{75} \mathrm{H}_{51} \mathrm{IrN}_{2} \mathrm{O}_{2}: \mathrm{C}$, 74.79; H, 4.27; N, 2.33. Found: C, 74.82; H.4.13; N, 2.24\%.

Complex 8. Yield: $60 \% .{ }^{1} \mathrm{H}$ NMR $\left(\delta, \mathrm{CDCl}_{3}\right): 1.94(\mathrm{~s}, 6 \mathrm{H}$, $\mathrm{CH}_{3}$-acac), 3.69 (s, 6H, $\left.\mathrm{OCH}_{3}\right), 3.73\left(\mathrm{~s}, 6 \mathrm{H}, \mathrm{OCH}_{3}\right), 5.33$ (s, $1 \mathrm{H}$, CH-acac), 6.22-6.25 (m, 2H, Ar), 6.40-6.42 (m, 2H, Ar), 6.376.64 (m, 12H, Ar), 6.65-6.86 (m, 16H, Ar), 7.04-7.06 (m, 6H, Ar), 7.17-7.23 (m, 8H, Ar), 7.28-7.35 (m, 6H, Ar), 7.47-7.50 (m, 2H, $\mathrm{Ar}), 7.60-7.68$ (m, 8H, Ar). ${ }^{13} \mathrm{C} \mathrm{NMR}\left(\delta, \mathrm{CDCl}_{3}\right)$ : 28.5, 31.7, 55.0, 101.4, 110.2, 112.2, 112.3, 112.5, 116.7, 122.7, 123.8, 125.3, 125.9, $126.8,127.5,127.9,128.5,129.6,130.1,130.2,131.4,132.5,132.7$, 133.1, 133.6, 135.9, 136.6, 138.7, 139.4, 140.1, 140.5, 140.7, 141.2, 142.1, 148.5, 157.0, 157.3, 164.2, 184.9. FAB MS(m/z): 1711.5 $\left(\mathrm{M}^{+}\right)$. Anal. Calcd for $\mathrm{C}_{107} \mathrm{H}_{81} \mathrm{IrN}_{4} \mathrm{O}_{6}$ : C, 75.11; H, 4.77; N, 3.27. Found: C, 74.83; H, 4.83; N, 3.16\%.

\section{LED Fabrication and measurements}

Compound BCP (2.9-dimethyl-4,7-diphenyl-1,10-phenanthroline) was purchased from Aldrich and used as received. The 
electron-transporting materials, $\mathrm{Alq}_{3}$ (tris(8-hydroxyquinoline) aluminium) $)^{25}$ and PPO (2-(4-tert-butylphenyl)-5-(pyren-1-yl)1,3,4-oxadiazole) ${ }^{26}$ were synthesized according to literature procedures and were sublimed prior to use. Prepatterned ITO substrates with an effective individual device area of $3.14 \mathrm{~mm}^{2}$ were cleaned as described in a previous report. ${ }^{27}$ A PVK:Ir complex (device I) or PVK:Ir Complex:PPO film (device II) was spin cast first. In device I, a 10-nm-thick BCP acting as a hole and exciton blocking layer (HBL) and 20-nm-thick $\mathrm{Alq}_{3}$ layer as an electron transport layer were then deposited sequentially. Finally, a thin layer of LiF (10 A) followed by aluminium (1000 $)$ ) was deposited as the cathode. The $I-V$ curve was measured on a Keithley 2400 Source meter in the ambient environment. Light intensity was measured with a Newport 1835 optical meter.

\section{Structural determination of complex 6}

Red crystals of $\mathbf{6}$ were grown from a dichloromethane solution layered with hexane at room temperature. Relevant crystal data collection and refinement are summarized in Table 1. Selected bond lengths and bond angles are given in Table 2. The space group $(P \overline{1})$ was determined from the systematic absence of specific reflections; successful refinement of the structure confirmed the space group assignment. Direct methods were used to locate the Ir atom, whereas subsequent cycles of least-squares refinements and difference Fourier map were used to locate the remaining non-hydrogen atoms. Hydrogen atoms were placed at calculated positions except for the $\mathrm{O}-\mathrm{H}$ bonds of the water molecule which were fixed at $0.85 \AA$. All calculations were performed using the SHELX software package.

CCDC reference number 294665.

For crystallographic data in CIF or other electronic format see DOI: $10.1039 / \mathrm{b} 618311 \mathrm{e}$

Table 1 Crystal data and structure refinement details for $\mathbf{6}$

\begin{tabular}{ll}
\hline Empirical formula & $\mathrm{C}_{71} \mathrm{H}_{47} \mathrm{IrN}_{2} \mathrm{O}_{2} \cdot 3 \mathrm{CH}_{2} \mathrm{Cl}_{2} \cdot \mathrm{H}_{2} \mathrm{O}$ \\
$M$ & 1425.10 \\
$T / \mathrm{K}$ & $100(1)$ \\
$\lambda / \AA$ & 0.71073 \\
Crystal system & Triclinic \\
space group & $P \overline{1}$ \\
$a / \AA$ & $12.2327(4)$ \\
$b / \AA$ & $13.1476(4)$ \\
$c / \AA$ & $20.8703(6)$ \\
$a /{ }^{\circ}$ & $83.244(2)$ \\
$\beta /{ }^{\circ}$ & $73.8030(10)$ \\
$\gamma /{ }^{\circ}$ & $77.3430(10)$ \\
$V / \AA^{3}$ & $3139.30(17)$ \\
$Z$ & 2 \\
$C$ Calcd density/Mg m & \\
$\mu / \mathrm{mm}^{-1}$ & 1.508 \\
$F(000)$ & 2.433 \\
Crystal size/mm & 1432 \\
$\theta$ range, data collection/ & \\
& $0.38 \times 0.24 \times 0.20$ \\
No. of reflns collected & 1.02 to $25.03,-13 \leq h \leq 14$, \\
No. of indep. reflns & $-15 \leq k \leq 15,0 \leq l \leq 24$ \\
Refinement method & 11103 \\
No.of data/restraints/parameters & 11103 \\
Goodness-of-fit on $F^{2}$ & Full-matrix least-squares on $F^{2}$ \\
Final $R$ indices $(I>2 \sigma(I)): R 1, w R 2$ & $11103 / 2 / 687$ \\
$R$ indices (all data): $R 1, w 2$ & 1.071 \\
\hline & $0.0278,0.0755$ \\
\hline & $0.0293,0.0768$ \\
\hline &
\end{tabular}

Table 2 Selected bond lengths $(\AA)$ and angles $\left({ }^{\circ}\right)$ for $\mathbf{6}$

\begin{tabular}{lrlr}
\hline Ir-C(11) & $1.995(3)$ & $\mathrm{Ir}-\mathrm{N}(2)$ & $2.017(3)$ \\
$\mathrm{Ir}-\mathrm{C}(61)$ & $1.996(3)$ & $\mathrm{Ir}-\mathrm{O}(1)$ & $2.128(2)$ \\
$\mathrm{Ir}-\mathrm{N}(1)$ & $2.016(3)$ & $\mathrm{Ir}-\mathrm{O}(2)$ & $2.140(2)$ \\
& & & \\
$\mathrm{C}(11)-\mathrm{Ir}-\mathrm{C}(61)$ & $96.77(13)$ & $\mathrm{N}(1)-\mathrm{Ir}-\mathrm{O}(1)$ & $92.83(10)$ \\
$\mathrm{C}(11)-\mathrm{Ir}-\mathrm{N}(1)$ & $80.69(13)$ & $\mathrm{N}(2)-\mathrm{Ir}-\mathrm{O}(1)$ & $81.84(10)$ \\
$\mathrm{C}(61)-\mathrm{Ir}-\mathrm{N}(1)$ & $103.68(13)$ & $\mathrm{C}(11)-\mathrm{Ir}-\mathrm{O}(2)$ & $87.12(12)$ \\
$\mathrm{C}(11)-\mathrm{Ir}-\mathrm{N}(2)$ & $104.46(13)$ & $\mathrm{C}(61)-\mathrm{Ir}-\mathrm{O}(2)$ & $173.31(12)$ \\
$\mathrm{C}(61)-\mathrm{Ir}-\mathrm{N}(2)$ & $80.26(13)$ & $\mathrm{N}(1)-\mathrm{Ir}-\mathrm{O}(2)$ & $82.28(10)$ \\
$\mathrm{N}(1)-\mathrm{Ir}-\mathrm{N}(2)$ & $173.25(11)$ & $\mathrm{N}(2)-\mathrm{Ir}-\mathrm{O}(2)$ & $93.52(11)$ \\
$\mathrm{C}(11)-\mathrm{Ir}-\mathrm{O}(1)$ & $173.17(12)$ & $\mathrm{O}(1)-\mathrm{Ir}-\mathrm{O}(2)$ & $89.87(9)$ \\
$\mathrm{C}(61)-\mathrm{Ir}-\mathrm{O}(1)$ & $86.83(12)$ & & \\
\hline
\end{tabular}

\section{Computational methodology}

To obtain the excitation energies of complex 6, we applied timedependent density function theory (TDDFT), in which the B3LYP functional was adopted. The geometry of complex $\mathbf{6}$ was based upon its X-ray structure. The basis set used is LANL2DZ for iridium, and $6-31 \mathrm{G}$ for the other elements. The calculation was performed with the Gaussian 03 program. ${ }^{28}$ Additionally, though being time consuming, the solvent effect on the absorption energies in $\mathrm{CH}_{2} \mathrm{Cl}_{2}$ are also considered by using an implicit solvation model IEFPCM with the same DFT functional and basis set. ${ }^{29}$ To save the computational resource, we only consider the solvent effect on the absorption energy of the lower lying states up to $S_{2}$ and $T_{2}$.

\section{Results and discussion}

\section{Synthesis and structure}

The structures of ligands and complexes are depicted in Charts 1 and 2. The ligands were synthesized by employing a DielsAlder [4 2] cycloaddition reaction ${ }^{22}$ involving the appropriately substituted cyclopentadienone and the corresponding terminal acetylene in diphenyl ether at $200{ }^{\circ} \mathrm{C}$ (Scheme 2).

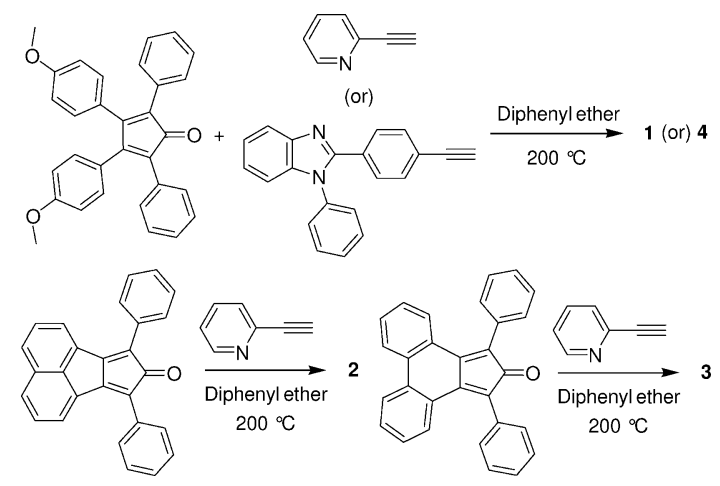

Scheme 2

The ligands were obtained in moderate yields (60-80\%) and were either colorless or yellow. The required complexes were obtained in two steps: (i) chloro-bridged dinuclear complexes by the treatment of the ligands with $\mathrm{IrCl}_{3} \cdot x \mathrm{H}_{2} \mathrm{O}$ in 2-methoxyethanol. (ii) These dinuclear complexes were cleaved by reaction with acetylacetone in the presence of sodium carbonate to obtain the mononuclear heteroleptic complexes, featuring the sterically demanding $\mathrm{CN}$ donor ligands and acetylacetonate auxiliary 
ligand. The as prepared complexes were purified by column chromatography, and the yield ranged from 55 to $80 \%$.

All the new compounds were thoroughly characterized by NMR $\left({ }^{1} \mathrm{H}\right.$ and $\left.{ }^{13} \mathrm{C}\right)$, mass spectra and elemental analyses. The spectral characteristics were in accordance with the structural compositions expected for the compounds. Since no broadening of the peaks was noticed in the ${ }^{1} \mathrm{H}$ NMR spectra it is believed that there exists only one isomer for these complexes. The structure of complex 6 was also confirmed by single crystal X-ray diffraction studies. In addition to the molecule $\mathbf{6}$, each asymmetric unit also contains three dichloromethane and one water molecules. As for the molecular structure displayed in Fig. 1, the iridium adopts an octahedral coordination environment with cis- $\mathrm{C}-\mathrm{C}$, cis-O-O and trans $-\mathrm{N}-\mathrm{N}$ donor dispositions. The average $\mathrm{Ir}-\mathrm{C}, \mathrm{Ir}-\mathrm{N}$ and $\mathrm{Ir}-\mathrm{O}$ distances are 1.996 (3), 2.017 (3), and 2.134 (2) A, respectively. These values are close to that observed for $\operatorname{Ir}(\mathrm{ppy})_{2}(\mathrm{acac})(2.003$ (9), 2.010 (9), 2.146 (6)). ${ }^{30}$ A slight deviation of the perfect octahedron is evident from the C-Ir-C (96.77 (13) $)$, O- $\mathrm{Ir}-\mathrm{O}$ $\left(89.87(9)^{\circ}\right)$, and $\mathrm{N}-\mathrm{Ir}-\mathrm{N}\left(173.25(11)^{\circ}\right)$ angles. The $\mathrm{C}-\mathrm{Ir}-\mathrm{C}$ angle is slightly wider when compared to that observed for $\operatorname{Ir}(\mathrm{ppy})_{2}$ (acac) $\left(95.2(5)^{\circ}\right)$. Consequently, the $\mathrm{N}-\mathrm{Ir}-\mathrm{N}$ angle is narrowed $\left(3^{\circ}\right)$ as compared to that observed in the $\operatorname{Ir}(\mathrm{ppy})_{2}(\mathrm{acac})$ complex. We attribute the above observations to the steric effect of the rigid, bulky ligand. The steric dictation on the coordination sphere is more evident from the $\mathrm{N}-\mathrm{Ir}-\mathrm{C}$ bite angles (av. $\left.80.48(13)^{\circ}\right)$ and the $\mathrm{N}-\mathrm{Ir}-\mathrm{C}$ inter-ligand angles (av. $104.07(13)^{\circ}$ ). The former is slightly shorter $\left(c f .81 .7(4)^{\circ}\right)$, and the latter is wider $\left(c f .95 .8(4)^{\circ}\right)$ than in $\operatorname{Ir}(\mathrm{ppy})_{2}(\mathrm{acac})$. All other distances and angles of the ligand are within the normal range. It is important to note that the pyridyl ring of each cyclometalated ligand is somewhat parallel to one of the dangling phenyl rings from the other cyclometalated ligand, and the distance between the centroids of the two rings is $\sim 3.7 \AA$. Such a $\pi-\pi$ interaction may result in low emission quantum yields for the complexes 5-7 in solution (vide infra). In comparison, the intermolecular $\pi-\pi$ interactions seem negligible.

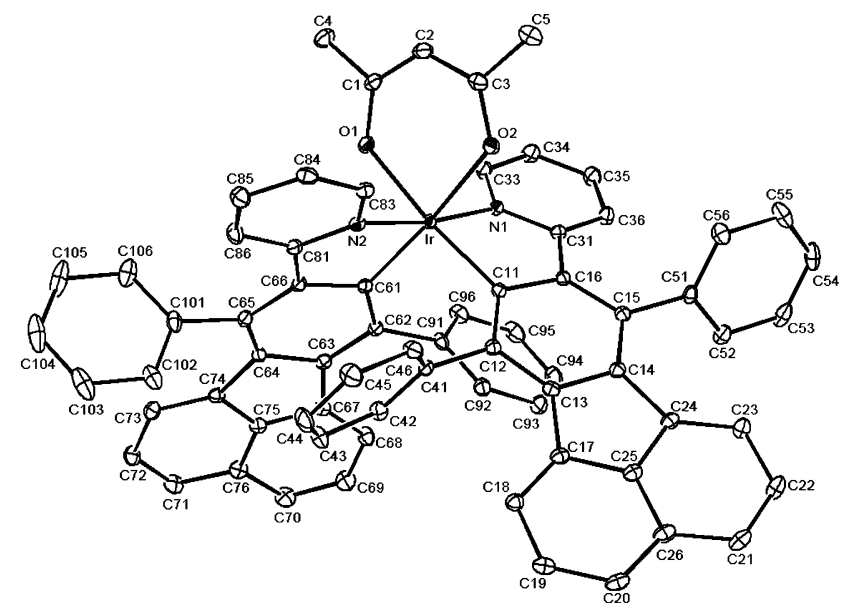

Fig. 1 Molecular structure of the complex 6 (the solvent molecules and hydrogen atoms are removed for clarity). The thermal ellipsoids are drawn at the $30 \%$ probability level.

\section{Absorption spectra}

Complexes 5-8 are either deep yellow or red in color, depending on the cyclometalating ligands. This is clearly manifested in the absorption spectra of the complexes. The absorption profiles of the ligands and the complexes recorded in dichloromethane solution are displayed in Fig. 2 and 3. All the ligands except 2 possess $\pi-\pi^{*}$ transition bands below $350 \mathrm{~nm}$ (Fig. 2). ${ }^{31}$ The absorption wavelengths of the $\pi-\pi^{*}$ transition bands are in the order of $\mathbf{1}<\mathbf{4} \approx$ $\mathbf{3}<\mathbf{2}$, consistent with the degree of electronic delocalization in the ligands. The peak wavelength at $374 \mathrm{~nm}$ for ligand $\mathbf{2}$ may originate from the fluoranthene segment. ${ }^{22}$ Compound $\mathbf{3}$ also possesses a fused aromatic segment, triphenylene. However, its associated $\pi-$ $\pi^{*}$ transition bands appear to be at shorter wavelengths because the fluoranthene segment has a smaller $\pi-\pi^{*}$ transition energy than the triphenylene analogue. ${ }^{32}$ In comparison to compound 4, the shorter absorption wavelength in compound $\mathbf{1}$ may be attributed to its less effective conjugation length since no more than three aromatic rings are linked in para form for favourable conjugation. Comparing Fig. 2 and 3, it is obvious that the ligand centered peaks for all the complexes, to certain degrees, are perturbed due to the presence of the metal center. In complexes $\mathbf{5}$ and $\mathbf{8}$, an additional three less intense transitions were noticed,

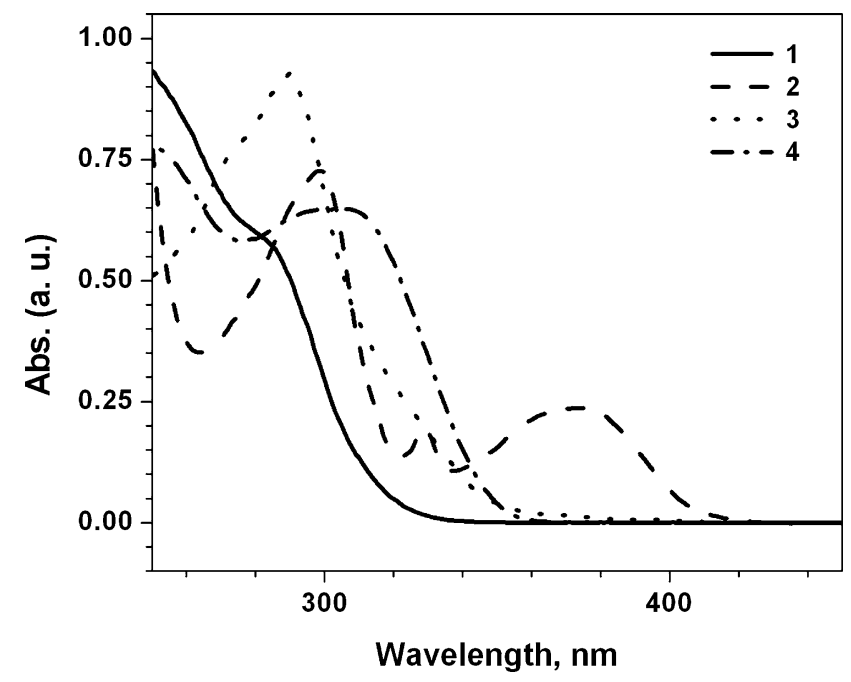

Fig. 2 Absorption spectra of the ligands $\mathbf{1 - 4}$ recorded in $\mathrm{CH}_{2} \mathrm{Cl}_{2}$ solutions.

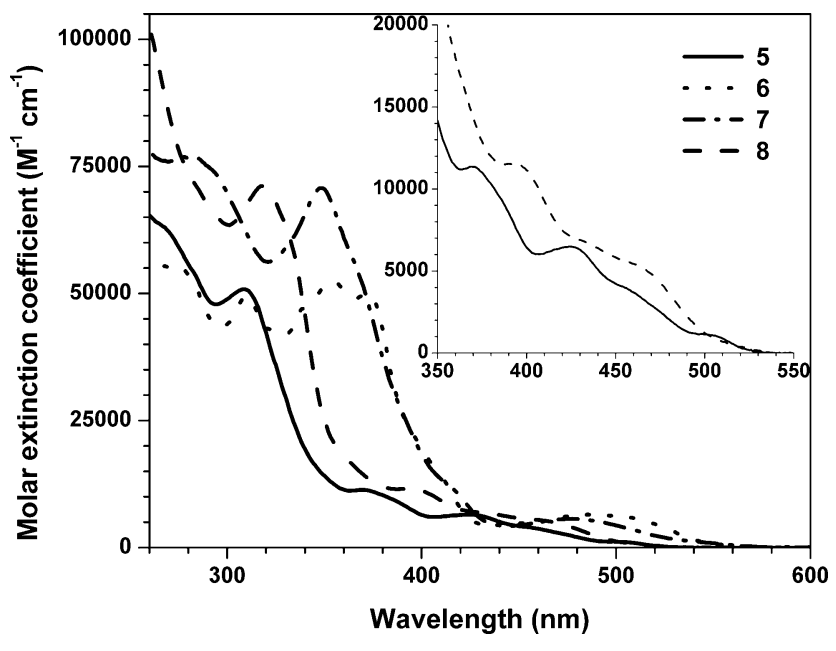

Fig. 3 Absorption spectra of the complexes 5-8 recorded in $\mathrm{CH}_{2} \mathrm{Cl}_{2}$ (inset shows the zoomed MLCT region for the complexes $\mathbf{5}$ and $\mathbf{8}$ ). 
while in complexes 6 and 7 , a prominent red-shifted absorption was identified above $450 \mathrm{~nm}$. These bands were reasonably ascribed to the MLCT transitions. ${ }^{1,4}$ It is interesting to compare the MLCT absorption peak wavelengths in the control complexes $\operatorname{Ir}(\mathrm{ppy})_{2}(\mathrm{acac})^{33}$ and $\operatorname{Ir}(\mathrm{pbi})_{2}(\mathrm{acac})^{9}$ with those of the complexes prepared in the current work. The salient spectral features derived from absorption studies enable us to gain insights into the role of the sterically hindered ligand on the electronic structure of the metal fragment. There is only slight red-shift $(c a .10 \mathrm{~nm})$ in the MLCT transitions of $\mathbf{5}$ and $\mathbf{8}$ when compared to the corresponding transitions with the control complexes. Apparently, the peripheral phenyl rings do not lead to much conjugation because they are skew with respect to the central phenyl rings, as evidenced from the structure of $\mathbf{6}$ (vide supra). In contrast, better conjugation is expected in ligands $\mathbf{2}$ and $\mathbf{3}$ due to the presence of polyaromatic segments. Accordingly, the resulting HOMO-LUMO energy gap leads to more pronounced red-shifted MLCT absorption peaks for their corresponding complexes $\mathbf{6}$ and $\mathbf{7}$ compared to the control complex $\operatorname{Ir}(\mathrm{ppy})_{2}(\mathrm{acac})^{34,15 a}$

\section{Emission spectra}

The luminescence spectra of the ligands and complexes were measured in dichloromethane and toluene, respectively. The spectra are displayed in Fig. 4 and 5, and the pertinent photophysical data are collected in Table 3. The complexes emit green or red in both solution and the solid state at room temperature. The emission peak wavelength of the bulky complexes is redshifted when compared to that of the control complexes, and the magnitude of the shift is dependent on the conjugation of the cyclometalating aromatic segment. ${ }^{1 b, 13 b, 35}$ Accordingly, complexes 5 and $\mathbf{8}$ are green-emitting species, while complexes $\mathbf{6}$ and $\mathbf{7}$ emit in the red due to the presence of the fluoranthene and triphenylene segments. As supported by the theoretical approach (vide infra), the emission is principally derived from the MLCT and $\pi-\pi^{*}$ states of the cyclometalated ligand. Moreover, the emission quantum yield of the complexes seems to be dependent on the interaction mode between metal and ligand sites. Type "A" complexes (57) possess low quantum yield, while the type "B" complex (8) displays moderate emission efficiency. The low solution quantum

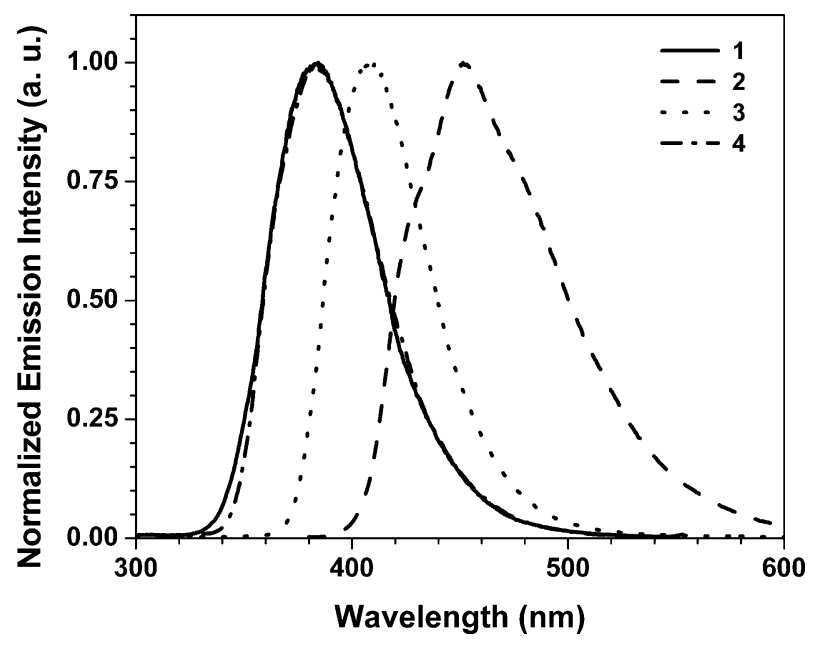

Fig. 4 Emission spectra of the ligands 1-4 recorded in $\mathrm{CH}_{2} \mathrm{Cl}_{2}$ solution at room temperature.

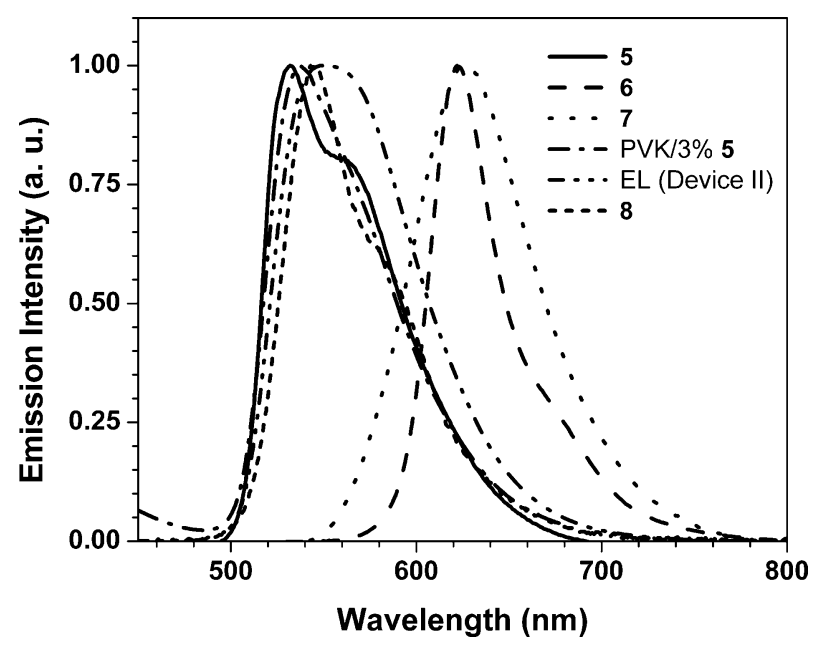

Fig. 5 Emission spectra of the complexes 5-8 recorded in toluene solution, $3 \% \mathbf{5}$ doped in PVK film and EL spectra of device II.

yields of complexes 5-7 stem from the close contact of the pyridyl ring and the dangling phenyl ring nearby (vide supra). Support of this viewpoint is given by the significantly large non-radiative decay rate constant deduced for 5-7 (see Table 3). Complexes 5 and $\mathbf{8}$ display phosphorescence lifetimes similar to those of the control complexes $\left(\operatorname{Ir}(\mathrm{ppy})_{2}(\mathrm{acac})\right.$ and $\operatorname{Ir}(\mathrm{pbi})_{2}(\mathrm{acac})$. However, a significant two-fold (7) and four-fold (6) enhancement in lifetime is observed for the complexes which possess extended polyaromatic conjugation in the $\sigma$-coordinating ligand segment. This result clearly supports the involvement of the ligand in the excited state properties of the complexes. ${ }^{36}$ These lifetime values appear to fall in the range of bis-cyclometalated ${ }^{31}$ and tris-cyclometalated ${ }^{21}$ iridium complexes. The distinct nonradiative decay constant for $\mathbf{5}$ among the four complexes accounts for its relatively small quantum yield.

\section{Electrochemical properties}

Electrochemical characteristics of the complexes were studied by using cyclic voltammetric methods in dichloromethane and the redox potentials are reported in Table 3. All complexes exhibit a quasi-reversible one-electron oxidation wave ranging from 0.25 to $0.29 \mathrm{~V} \mathrm{vs}$. ferrocene, which is attributed to the oxidation of iridium(III). The larger peak-to-peak separation $\left(\Delta E_{\mathrm{p}}\right)$ observed in the present study suggests a significant structural reorganization during the redox process. ${ }^{37}$ The pyridine-containing complexes, 5-7 have a higher oxidation potential $(0.25-0.27 \mathrm{~V})$ than the control complex, $\operatorname{Ir}(\mathrm{ppy})_{2}(\mathrm{acac})(0.46 \mathrm{~V}){ }^{33}$ while complex 8 has an oxidation potential $(0.29 \mathrm{~V})$ similar to that of $\operatorname{Ir}(\mathrm{pbi})_{2}(\mathrm{acac})$ $(0.30 \mathrm{~V}) .^{9}$ We attributed this observation to the influence of the sterically hindered moiety on the HOMO. Apparently the sterically hindered moiety is closer to the cyclometalated phenyl ring in 57. All complexes exhibit an irreversible reduction wave attributed to the reduction of the ligand. Complexes $\mathbf{6}$ and $\mathbf{7}$ have more positive potential, possibly due to the more delocalized nature of the fluoranthene and triphenylene segments. The differences in the oxidation and reduction potentials for the complexes are in the order of $\mathbf{6}<\mathbf{7}<\mathbf{8}<\mathbf{5}$. Though the irreversible nature of the reduction peak prevents us from more accurate estimation, this trend, however, is consistent with the absorption and emission spectra (vide supra). 


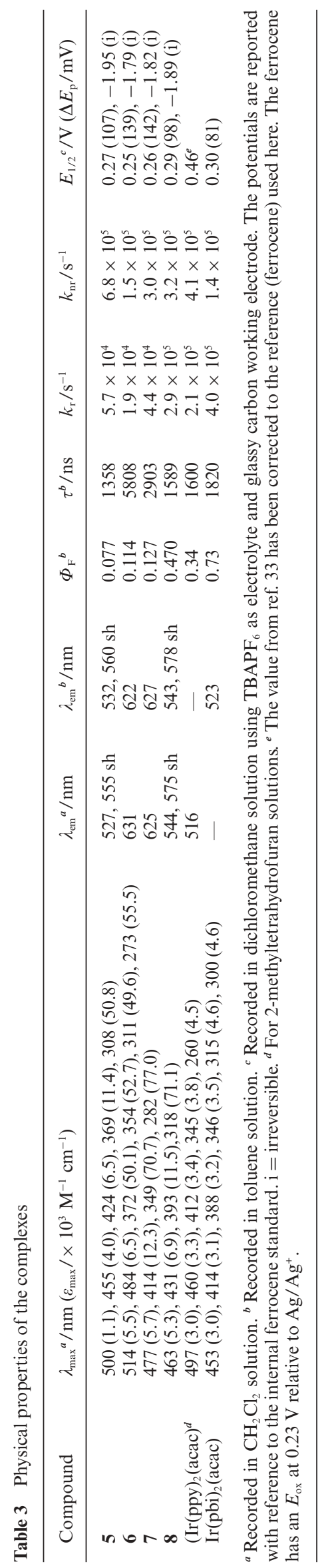

\section{MO Calculations}

To gain more insight into the photophysical properties of the complexes, TDDFT calculations (see Experimental section) on the molecular orbitals involved in the transitions was carried out for 6. The features of the two lowest unoccupied (LUMO and LUMO + 1) and the two highest occupied (HOMO and HOMO - 1) frontier orbitals mainly involved in the transition are depicted in Fig. 6, while the descriptions and energy gaps of each transition are listed in Table 4. Qualitatively, the stronger singlet absorptions for 6 are calculated at $\sim 478,412$, and $390 \mathrm{~nm}$, the results of which are in agreement with the observed absorption spectral profiles. Moreover, the lowest triplet state is calculated to be $\sim 572 \mathrm{~nm}$, which is also consistent with the $0-0$ onset $(\sim 580 \mathrm{~nm})$ of the corresponding phosphorescence spectrum (see Fig. 5), supporting the validity of the TDDFT approach. Evidently, the electron densities of both the HOMO and HOMO - 1 are located largely on the metal and the fluoranthene segment of $\mathbf{6}$, whereas those of the LUMO and LUMO + 1 are distributed largely on the pyridyl moiety and partly on the fluoranthene segment and nonbonding $\mathrm{d}$ orbital of the central metal, indicating that the lowest transition is ascribed to metal-to-ligand charge transfer (MLCT) mixed with $\pi$ (fluoranthene) $\rightarrow \pi^{*}$ (pyridine) character. The dominance of the HOMO $\rightarrow$ LUMO transition (see Table 4), in which MLCT has a great contribution, qualitatively explains the broad, featureless emission band with fast radiative decay time. Accordingly, it is reasonable to expect that by introducing more extended polyaromatic conjugation into the $\sigma$-coordinating ligand segment, such as in $\mathbf{6}$ and $\mathbf{7}$, there should be more $\pi \pi^{*}$ contribution to the $T_{1}$ state in complex 7. Since the $T_{1} \rightarrow S_{0}$ transition with a $\pi \pi^{*}$ configuration does not directly involve the heavy metal $(\operatorname{Ir}(\mathrm{III})) \mathrm{d}_{\pi}$ orbital as well as lacking the orbital flipping that can be borrowed by the flip of spin, the transition dipole is small hence the resulting radiative lifetime is expected to be longer, consistent with that observed experimentally (see Table 3). The

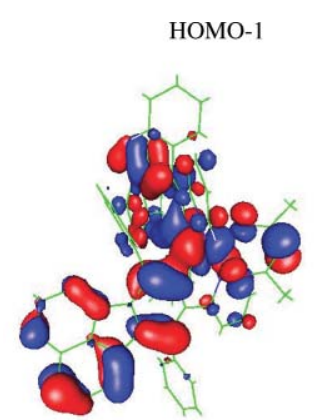

LUMO

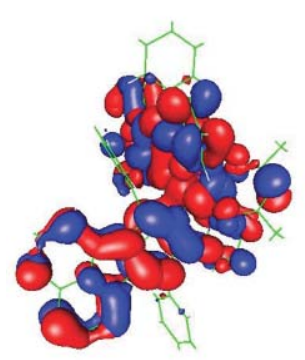

HOMO

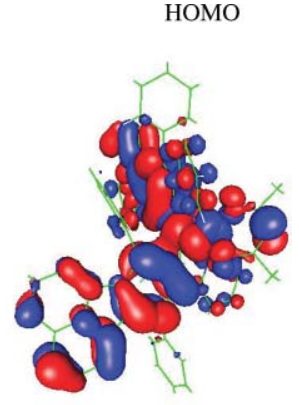

LUMO+1

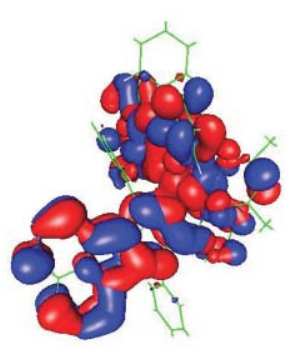

Fig. 6 Selected frontier orbitals for complex 6. 
Table 4 Calculated energy levels of the lower lying transitions of complex 6

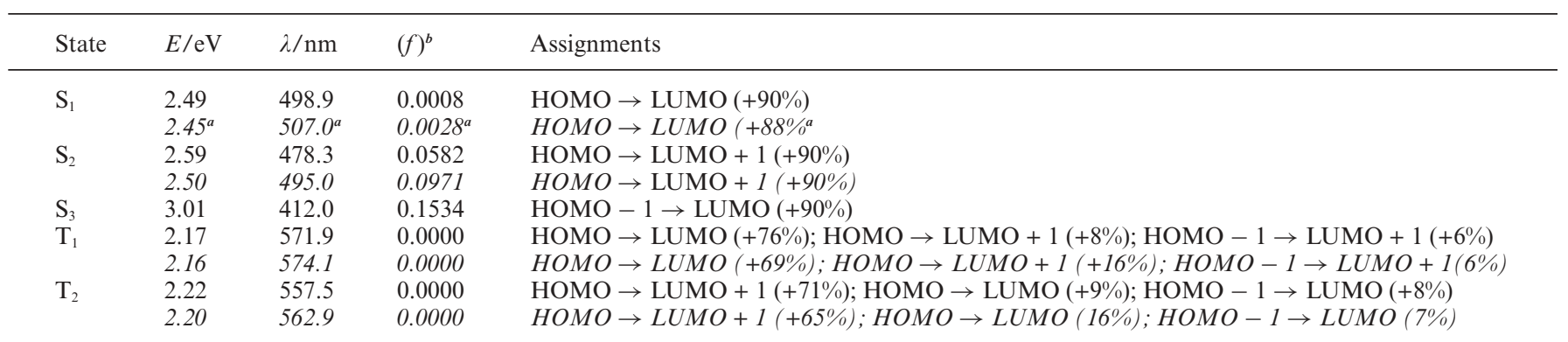

${ }^{a}$ The values in Italic type are the results considering solvent effects. ${ }^{b}$ Oscillator strength.

aforementioned theoretical approaches were performed under gas conditions. In order to evaluate the solvation effect, the absorption energy gap with the addition of $\mathrm{CH}_{2} \mathrm{Cl}_{2}$ was also calculated and listed in Table 4 (see Experimental section for details). As shown in Table 4, upon considering the solvent effect, the absorption peaks in both the singlet and triplet states are only slightly red-shifted and are closer to those observed experimentally. Nevertheless, the involved frontier orbitals remain unchanged. Considering the time-consuming computation upon incorporating the solvation effect, theoretical approaches in the gas phase seem to be sufficient for the rationalization.

\section{Electroluminescent properties}

The HOMO energy values derived from the oxidation potential (Table 3) fall in the range 5.05-5.09 eV. This is sufficiently high to facilitate hole injection in the molecular layer. Due to the favourable redox and emission characteristics, the complexes are perceived as suitable for electroluminescent applications. Subsequently, the complexes were applied in organic light-emitting diodes as dopants. Two types of devices were fabricated using 5 and 8 as dopant in a polyvinyl carbazole (PVK) layer (Fig. 7). They are: (I) $\mathrm{ITO} / 3 \% 5$ (or 8 ) in PVK $(70 \mathrm{~nm}) / \mathrm{BCP}(10 \mathrm{~nm}) / \mathrm{Alq}_{3}$ $(20 \mathrm{~nm}) / \mathrm{LiF}(1 \mathrm{~nm}) / \mathrm{Al}(100 \mathrm{~nm})$, and (II) $\mathrm{ITO} / 3 \% 5$ (or 8) and $40 \%$ PPO in PVK (100 nm)/LiF (1 nm)/Al (100 nm). The first device adopts a multi-layer architecture consisting of an Ir doped hole-transport layer, a hole-blocking layer, and an electron-transport layer. In the second device, a single-layer configuration containing a blend of hole-transporting PVK and electron-transporting PPO was used to dope the Ir complex. It was found that the latter device did not require a hole-blocking layer to restrict the recombination zone inside the PVK layer. The EL spectra of the two devices closely resemble the solid state PL realized for the PVK : Ir complex blend (Fig. 5). A slight red-tailing noticed in the EL spectra of the devices may be attributed to the medium perturbation. The pertinent parameters are collected in Table 5 , and the $I-V-L$ characteristics observed for devices 5 are plotted in Fig. 8. Device II for $\mathbf{5}$ exhibited maximum brightness, $26450 \mathrm{~cd} \mathrm{~m}^{-2}$ at $30 \mathrm{~V}$, and a maximum current efficiency of $40 \mathrm{~cd}$ $\mathrm{A}^{-1}$. The better performance of device II as compared to that of I is ascribed to the improved balance in the charge transport in the HTL : ETL blend layer. ${ }^{38}$ The maximum external quantum efficiency (I, 4.4\%; II, 6.69\%) for both devices of 5 are comparable to that $(\sim 10 \%)$ of the vacuum-deposited multi-layer device of $\operatorname{Ir}(\mathrm{ppy})_{2}$ (acac).$^{33}$ However, the maximum power efficiency for both
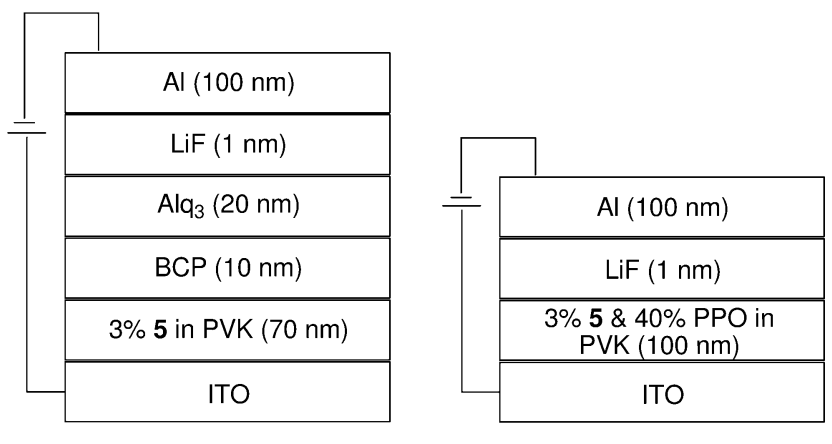

Device I
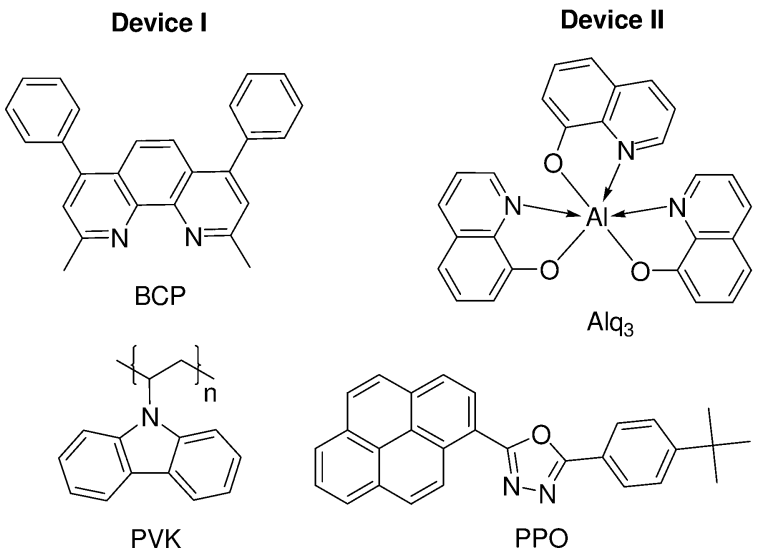

Fig. 7 Device configurations and the structure of the constituent materials.

devices (I, $\left.7.64 \mathrm{~lm} \mathrm{~W}^{-1} ; \mathrm{II}, 6.69 \mathrm{~lm} \mathrm{~W}^{-1}\right)$ are inferior to that $(\sim 18 \mathrm{~lm}$ $\mathrm{W}^{-1}$ ) of $\operatorname{Ir}(\mathrm{ppy})_{2}(\mathrm{acac})$. This may be due to the low phosphorescence quantum yield $(7.7 \%)$ of 5 compared to $\operatorname{Ir}(\mathrm{ppy})_{2}$ (acac) (34\%). In comparison, the device performance appears to be better than the single-layer device of the complex composed of a fac-tris(2-phenylpyridyl)iridium(III) core and similar sterically crowded dendron $(2.9 \%)$ reported by Burn's group. ${ }^{15 a}$ We speculate that the emission of the iridium core is well encapsulated by the three somewhat insulating ligands to allow efficient carrier injection. For both devices of $\mathbf{8}$, the maximum external quantum efficiency (I, 8.64\%; II, 3.85\%) and maximum power efficiency

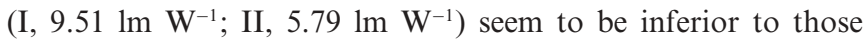
$\left(\sim 16.7 \% ; 20 \mathrm{~lm} \mathrm{~W} \mathrm{~m}^{-1}\right)$ of the vacuum-deposited multi-layer device of $\operatorname{Ir}(\mathrm{pbi})_{2}(\mathrm{acac}) .^{9}$ The cause of the low efficiency for the devices of $\mathbf{8}$ may be due to both encapsulation of the emitting core with somewhat insulating ligands as well as the imbalance in the carrier mobility. However, more studies are needed to understand the 
Table 5 Electroluminescent data for $\mathbf{5}$ and $\mathbf{8}^{a}$

\begin{tabular}{|c|c|c|c|c|}
\hline Device & I (5) & II (5) & I $(8)$ & II (8) \\
\hline$V_{\text {on }} / \mathrm{V}$ & 8.0 & 8.0 & 6.5 & 5.5 \\
\hline$L_{\max } / \mathrm{cd} \mathrm{m}^{-2}\left(V\right.$ at $\left.L_{\max },(\mathrm{V})\right)$ & $15264(28.5)$ & $26498(30)$ & $7125(22.5)$ & $5407(14.5)$ \\
\hline $\operatorname{CIE}(x, y)$ & $0.44,0.54$ & $0.43,0.56$ & $0.40,0.54$ & $0.41,0.56$ \\
\hline $\mathrm{fwhm} / \mathrm{nm}$ & 92 & 84 & 72 & 70 \\
\hline$\eta_{\mathrm{ext}} \max (\%)$ & 11.53 & 11.17 & 8.64 & 3.85 \\
\hline$\eta_{\mathrm{p} \text { max }} / 1 \mathrm{~m} \mathrm{\textrm {W } ^ { - 1 }}$ & 7.64 & 6.69 & 9.51 & 5.79 \\
\hline$\eta_{\mathrm{ext}}^{b}(\%)$ & 4.40 & 6.41 & 1.99 & 1.42 \\
\hline$\eta_{\mathrm{p}}{ }^{b} / \mathrm{lm} \mathrm{W}^{-1}$ & 1.71 & 2.61 & 0.99 & 1.18 \\
\hline$\eta_{\mathrm{c}}{ }^{b} / \mathrm{cd} \mathrm{A}^{-1}$ & 15.32 & 23.11 & 6.99 & 5.15 \\
\hline
\end{tabular}

${ }^{a}$ Legends: $L_{\max }$, maximum luminance; $L$, luminance; $V_{\text {on }}$, turn-on voltage; $V$, voltage; $\eta_{\text {ext,max }}$, maximum external quantum efficiency; $\eta_{\mathrm{p}, \max }$, maximum power efficiency; $\eta_{\mathrm{c}, \max }$, maximum current efficiency; $\eta_{\mathrm{ext}}$, external quantum efficiency; $\eta_{\mathrm{p}}$, power efficiency; $\eta_{\mathrm{c}}$, current efficiency; fwhm, full width at half maximum. ${ }^{b}$ At a current density of $100 \mathrm{~mA} \mathrm{~cm}^{-2} . V_{\text {on }}$ was obtained from the $x$-intercept of $\log ($ luminance) $v s$. applied voltage plot.

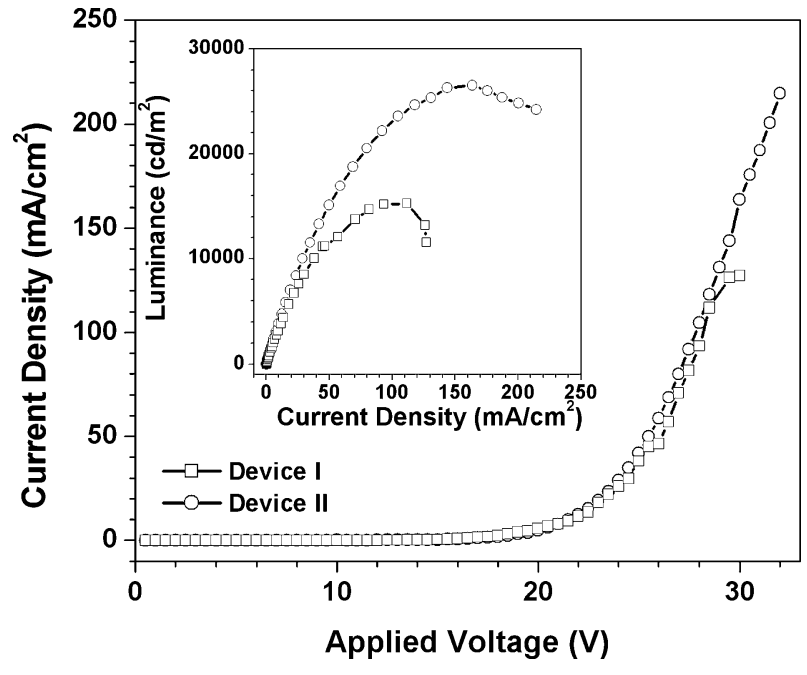

Fig. $8 I-V-L$ characteristics of the devices I and II containing the complex $\mathbf{5}$ as a dopant.

factors affecting the device performance. Fabrication of the devices for complex 6 was also attempted; unfortunately, the performance was poor. Besides poor carrier mobility and poor balance of carrier mobility, the low device efficiency, in part, may be attributed to the intramolecular $\pi-\pi$ interaction that leads to a rather low quantum yield of the complexes (vide supra). In yet another approach, we also carried out a concentration dependent experiment and found that the emission quantum yield of complex $\mathbf{5}$ in toluene dropped $\sim 25 \%$ as the concentration increased from $4.47 \times 10^{-5} \mathrm{M}$ to $1.35 \times 10^{-4} \mathrm{M}$. The results, in combination with the negligible improvement in device performance upon increasing the doping concentration, indicate that weak intermolecular interactions cannot be completely ruled out for explaining the low device efficiency.

\section{Conclusion}

In summary, we have synthesized and characterized a new series of cyclometalated iridium complexes bearing sterically demanding polyaromatic $\sigma$-coordination sites. Comprehensive structural characterization and photophysical behaviour of the corresponding complexes have been investigated. The results, in combination with theoretical approaches, address the correlation between the nature of the $\sigma$-coordinating ligand segment and the absorption/emission characteristics such as spectral profile, peak wavelength and relaxation dynamics. For complexes 5-8, a wide spectral tunability ranging from green to red has been achieved. Electroluminescent devices using a selected complex (5) as dopant in a polymer or polymer : ETL blend matrix are demonstrated with promising device parameters. Work focusing on promoting device engineering and its associated physical and photophysical properties is underway.

\section{Acknowledgements}

Financial support from Academia Sinica and National Taiwan University is gratefully acknowledged.

\section{References}

1 (a) C. S. K. Mak, A. Hayer, S. I. Pascu, S. E. Watkins, A. B. Holmes, A. Köhler and R. H. Friend, Chem. Commun., 2005, 4708; (b) K. R. J. Thomas, M. Velusamy, J. T. Lin, C.-H. Chien, Y.-T. Tao, Y. S. Wen, Y.-H. Hu and P.-T. Chou, Inorg. Chem., 2005, 44, 5677; (c) F. Lafolet, S. Welter, Z. Popovic and L. De Cola, J. Mater. Chem., 2005, 15, 2820; (d) M. Tavasli, S. Bettington, M. R. Bryce, H. A. Al Attar, F. B. Dias, S. A. King and P. Monkman, J. Mater. Chem., 2005, 15, 4963; (e) C.-H. Yang, K.-H. Fang, C.-H. Chen and I.-W. Sun, Chem. Commun., 2004, 2232; (f) P. Coppo, E. A. Plummer and L. De Cola, Chem. Commun., 2004, 1774; $(g)$ E. Holder, B. M. W. Langeveld and U. S. Schubert, $A d v$. Mater., 2005, 17, 1109; (h) R. C. Evans, P. Douglas and C. J. Winscom, Coord. Chem. Rev., 2006, 250, 2093.

2 (a) K. K.-W. Lo, C.-K. Li and J. S.-Y. Lau, Organometallics, 2005, 24, 4594; (b) K. K.-W. Lo, C.-K. Chung and N. Zhu, Chem.-Eur. J., 2006, 12, 1500 .

3 (a) Y.-L. Tung, S.-W. Lee, Y. Chi, L.-S. Chen, C.-F. Shu, F.-I. Wu, A. J. Carty, P.-T. Chou, S.-M. Peng and G.-H. Lee, Adv. Mater., 2005, 17, 1059; (b) J. Slinker, D. Bernards, P. L. Houston, H. D. Abruña, S. Bernhard and G. G. Malliaras, Chem. Commun., 2003, 2392; (c) C.-Y. Liu and A. J. Bard, J. Am. Chem. Soc., 2002, 124, 4190; (d) H. Rudmann, S. Shimada and M. F. Rubner, J. Am. Chem. Soc., 2002, 124, 4918.

4 (a) A. B. Tamayo, S. Garon, T. Sajoto, P. I. Djurovich, I. M. Tsyba, R. Bau and M. E. Thompson, Inorg. Chem., 2005, 44, 8723; (b) J. D. Slinker, A. A. Gorodetsky, M. S. Lowry, J. Wang, S. Parker, R. Rohl, S. Bernhard and G. G. Malliaras, J. Am. Chem. Soc., 2004, 126, 2763; 
(c) Md. K. Nazeeruddin, R. Humphry-Baker, D. Berner, S. Rivier, L. Zuppiroli and M. Graetzel, J. Am. Chem. Soc., 2003, 125, 8790.

5 (a) C. Adachi, M. A. Baldo, M. E. Thompson and S. R. Forrest, J. Appl. Phys., 2001, 90, 5048; (b) S. M. King, H. A. Al-Attar, R. J. Evans, A. Congreve, A. Beeby and A. P. Monkman, Adv. Funct. Mater., 2006, 16, 1043.

6 (a) A. S. Dhoot and N. C. Greenham, Adv. Mater., 2002, 14, 1834; (b) D. Wasserberg, S. P. Dudek, S. C. J. Meskers and R. A. J. Janssen, Chem. Phys. Lett., 2005, 411, 273.

7 (a) V. V. Grushin, N. Herron, D. D. LeCloux, W. J. Marshall, V. A. Petrov and Y. Wang, Chem. Commun., 2001, 1494; (b) W.-Y. Wong, G.-J. Zhou, X.-M. Yu, H.-S. Kwok and B.-Z. Tang, Adv. Funct. Mater. 2006, 16, 838

8 I. R. Laskar and T.-M. Chen, Chem. Mater, 2004, 16, 111.

9 W.-S. Huang, J. T. Lin, C.-H. Chien, Y.-T. Tao, S.-S. Sun and Y.-S. Wen, Chem. Mater., 2004, 16, 2480.

10 (a) D. K. Rayabarapu, B. M. J. S. Paulose, J.-P. Duan and C.-H. Cheng, Adv. Mater., 2005, 17, 349; (b) C. Jiang, W. Yang, J. Peng, S. Xiao and Y. Cao, Adv. Mater., 2004, 16, 537; (c) C.-H. Yang, C.-C. Tai and I.-W. Sun, J. Mater. Chem., 2004, 14, 947; (d) F.-I. Wu, H.-J. Su, C.-F. Shu, L. Luo, W.-G. Diau, C.-H. Cheng, J.-P. Duan and G.-H. Lee, J. Mater Chem., 2005, 15, 1035.

11 T.-H. Kwon, H. S. Cho, M. K. Kim, J.-W. Kim, J.-J. Kim, K. H. Lee, S. J. Park, I.-S. Shin, H. Kim, D. M. Shin, Y. K. Chung and J.-I. Hong, Organometallics, 2005, 24, 1578.

12 Y. You and S. Y. Park, J. Am. Chem. Soc., 2005, 127, 12438.

13 (a) C.-H. Yang, S.-W. Li, Y. Chi, Y.-M. Cheng, Y.-S. Yeh, P.-T. Chou, G.-H. Lee, C.-H. Wang and C.-F. Shu, Inorg. Chem., 2005, 44, 7770; (b) F.-M. Hwang, H.-Y. Chen, P.-S. Chen, C.-S. Liu, Y. Chi, C.-F. Shu, F.-I. Wu, P.-T. Chou, S.-M. Peng and G.-H. Lee, Inorg. Chem., 2005, 44, 1344; (c) S.-J. Yeh, M.-F. Wu, C.-T. Chen, Y.-H. Song, Y. Chi, M.-H. Ho, S.-F. Hsu and C. H. Chen, Adv. Mater., 2005, 17, 285.

14 K. Dedeian, J. Shi, N. Shepherd, E. Forsythe and D. C. Morton, Inorg Chem., 2005, 44, 4445.

15 (a) N. Cumpstey, R. N. Bera, P. L. Burn and I. D. W. Samuel, Macromolecules, 2005, 38, 9564; (b) M. J. Frampton, E. B. Namdas, S.-C. Lo, P. L. Burn and I. D. W. Samuel, J. Mater. Chem., 2004, 14, 2881; (c) S.-C. Lo, G. J. Richards, J. P. J. Markham, E. B. Namdas, S. Sharma, P. L. Burn and I. D. W. Samuel, Adv. Funct. Mater., 2005, 15, 1451; (d) J. Ding, J. Gao, Y. Cheng, Z. Xie, L. Wang, D. Ma, X. Jing and F. Wang, Adv. Funct. Mater., 2006, 16, 575; (e) S.-C. Lo, E. B. Namdas, C. P. Shipley, J. P. J. Markham, T. D. Anthopolous, P. L. Burn and I. D. W. Samuel, Org. Electron., 2006, 7, 85.

16 (a) H. Zhen, C. Jiang, W. Yang, J. Jiang, F. Huang and Y. Cao, Chem.Eur. J., 2005, 11, 5007; (b) A. J. Sandee, C. K. Williams, N. R. Evans, J. E. Davies, C. E. Boothby, A. Köhler, R. H. Friend and A. B. Holmes, J. Am. Chem. Soc., 2004, 126, 7041; (c) Y. You, S. H. Kim, H. K. Jung and S. Y. Park, Macromolecules, 2006, 39, 349.

17 R. E. Bauer, A. C. Grimsdale and K. Müllen, Top. Curr. Chem., 2005, 245, 253.

18 (a) K. R. J. Thomas, M. Velusamy, J. T. Lin, C.-H. Chuen and Y.-T. Tao, J. Mater. Chem., 2005, 15, 4453; (b) C. Huang, C.-G. Zhen, S. P. Su, K. P. Loh and Z.-K. Chen, Org. Lett., 2005, 7, 391

19 K. R. J. Thomas, M. Velusamy, J. T. Lin, S.-S. Sun, Y.-T. Tao and C.-H. Chuen, Chem. Commun., 2004, 2328.

20 R. C. Chiechi, R. J. Tseng, F. Marchioni, Y. Yang and F. Wudl, $A d v$ Mater., 2006, 18, 325.
21 A. Tsuboyama, H. Iwawaki, M. Furugori, T. Mukaide, J. Kamatani, S. Igawa, T. Moriyama, S. Miura, T. Takiguchi, S. Okada, M. Hoshino and K. Ueno, J. Am. Chem. Soc., 2003, 125, 12971.

22 (a) M. A. Ogliaruso, M. G. Romanelli and E. I. Becker, Chem. Rev., 1965, 65, 261; (b) M. Wehmeier, M. Wagner and K. Müllen, Chem.Eur. J., 2001, 7, 2197; (c) C. F. H. Allen and J. A. VanAllan, J. Org. Chem., 1952, 17, 845.

23 R. A. Pascal, D. V. Engen, B. Kahr and W. D. McMillan, J. Org. Chem., 1988, 53, 1687.

24 T. Sakamoto, M. Shiraiwa, Y. Kondo and H. Yamanaka, Synthesis, $1983,312$.

25 C. H. Chen and J. Shi, Coord. Chem. Rev., 1998, 171, 161

26 J. R. Atkinson and H. Eric, US Pat., 3600 383, 1967.

27 E. Balasubramaniam, Y.-T. Tao, A. Danel and P. Tomasik, Chem. Mater., 2000, 12, 2788.

28 M. J. Frisch, G. W. Trucks, H. B. Schlegel, G. E. Scuseria, M. A. Robb, J. R. Cheeseman, J. A. Montgomery, Jr., T. Vreyen, K. N. Kudin, J. C. Burant, J. M. Millam, S. S. Iyengar, J. Tomasi, V. Barone, B. Mennucci, M. Cossi, G. Scalmani, N. Rega, G. A. Petersson, H. Nakatsuji, M. Hada, M. Ehara, K. Toyota, R. Fukuda, J. Hasegawa, M. Ishida, T. Nakajima, Y. Honda, O. Kitao, H. Nakai, M. Klene, X. Li, J. E. Knox, H. P. Hratchian, J. B. Cross C. Adamo, J. Jaramillo, R. Gomperts, R. E. Stratmann, O. Yazyev, A. J. Austin, R. Cammi, C. Pomelli, J. W. Octhterski, P. Y. Ayala, K. Morokuma, G. A. Voth, P. Salvador, J. J. Dannenberg, V. G. Zakrzewski, S. Dapprich, A. D. Daniels, M. C. Strain, O. Farkas, D. K. Malick, A. D. Rabuck, K. Raghavachari, J. B. Foresman, J. V. Ortiz, Q. Cui, A. G. Baboul, S. Clifford, J. Cioslowski, B. B. Stefanov, G. Liu, A. Liashenko, P. Piskorz, I. Komaromi, R. L. Martin, D. J. Fox, T. Keith, M. A. Al-Laham, C. Y. Peng, A. Nanayakkara, M. Challacombe, P. M. W. Gill, B. Johnson, W. Chen, M. W. Wong, C. Gonzalez and J. A. Pople, Gaussian 03, Revision C.02, Gaussian, Inc., Pittsburgh, PA, 2004.

29 S. Miertus, E. Scrocco and J. Tomasi, Chem. Phys., 1981, 55, 117.

30 S. Lamansky, P. Djurovich, D. Murphy, F. Abdel-Razzaq, R. Kwong, I. Tsyba, M. Bortz, B. Mui, R. Bau and M. E. Thompson, Inorg. Chem., 2001, 40, 1704

31 D. Liu, S De Feyter, M. Cotlet, A. Stefan, U.-M. Wiesler, A. Herrmann, D. Grebel-Koehler, J. Qu, K. Müllen and F. C. De Schryver, Macromolecules, 2003, 36, 5918.

32 P. Bergmann and H. Paul, Chem. Ber., 1967, 100, 828.

33 S. Lamansky, P. Djurovich, D. Murphy, F. Abdel-Razzaq, H.-E. Lee, C. Adachi, P. E. Burrows, S. R. Forrest and M. E. Thompson, J. Am. Chem. Soc., 2001, 123, 4304.

34 (a) T. Tsuzuki, N. Shirasawa, T. Suzuki and S. Tokito, Adv. Mater., 2003, 15, 1455; (b) S.-C. Lo, E. B. Namdas, P. L. Burn and I. D. W. Samuel, Macromolecules, 2003, 36, 9721.

35 Y.-J. Su, H.-L. Huang, C.-L. Li, C.-H. Chien, Y.-T. Tao, P.-T. Chou, S. Datta and R.-S. Liu, Adv. Mater., 2003, 15, 884

36 T. Sajoto, P. I. Djurovich, A. Tamayo, M. Yousufuddin, R. Bau, M. E. Thompson, R. J. Holmes and S. R. Forrest, Inorg. Chem., 2005, 44, 7992.

37 P. Zanello, in Stereochemistry of Organometallic and Inorganic Compounds, ed. I. Bernal, Elsevier, Amsterdam, 1990, vol. 4, p. 181.

38 F.-C. Chen, Y. Yang, M. E. Thompson and J. Kido, Appl. Phys. Lett., 2002, 80, 2308; C. C. Wu, J. C. Sturm, R. A. Register, J. Tian, E. P. Dana and M. E Thompson, IEEE Trans. Electron Devices, 1997, 44, 1269. 